\title{
Decriminalize drugs and use public health
}

$\mathrm{C}$ anada's war on drugs has caused serious harm, particularly for the nation's most vulnerable, according to a Canadian Public Health Association (CPHA) policy paper released May 27.

The report, A New Approach to Managing Psychoactive Substances, calls for the decriminalization of drugs such as marijuana, heroin and cocaine, as well as strategies to reduce harm and address the social conditions underlying problem substance use.

"There's a better way to do this, and we believe it's the public health way," CPHA Executive Director Ian Culbert told delegates to the group's annual meeting in Toronto. "If you want to deal with drugs, you need to deal with the reasons why people use drugs."

According to Culbert, prohibition has engendered an environment that fuels the growth of illegal markets, organized crime, violent injuries, and the deaths of users, dealers and police. It also has negative public health consequences such as accelerating the spread of HIV and hepatitis $\mathrm{C}$, and increasing overdose deaths from contaminated drugs.

This approach is rooted in attitudes and evidence "going back to Victorian times" that do not reflect current scientific knowledge, he said.

The new policy paper outlines a "21st century approach" in which criminal prohibitions would be replaced by a public-health-focused regulatory program to manage the production, sale and distribution of currently illegal drugs. Under such a regime, "efforts are focused on addressing the social determinants of problematic substance use, moderating consumer demand for psychoactive substances, reducing harm, and improving the health of individual users, communities, and populations."

Among other recommended first steps, the report calls on the federal government to move the lead on its antidrug strategy back to Health Canada, reinstate harm reduction as a core element of national drug policy and

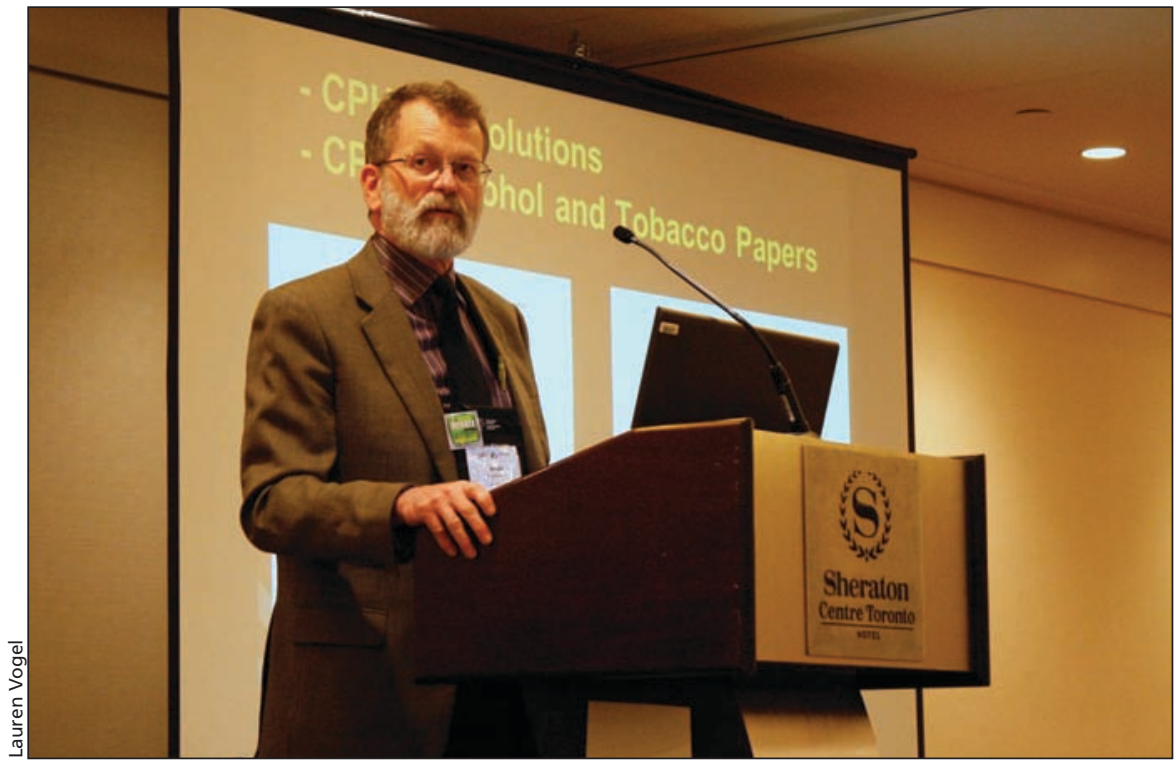

Drug policies should emphasize health, not punishment, says Dr. Brian Emerson, a medical consultant with the BC Ministry of Health.

review the effectiveness, costs and benefits of current policies.

Currently, Canada spends an estimated $\$ 8.2$ billion on harms associated with illegal drugs; $\$ 5.4$ billion of this is related to law enforcement.

The report also counters concerns that decriminalization will tacitly encourage drug use, noting that current prohibitions haven't proven to be effective deterrents. For example, 28\% of Canadian youth aged 11,13 and 15 report recent marijuana use - the highest rate among western nations.

Meanwhile, the threat of prosecution drives people who use illegal drugs away from prevention and care services into environments with increased risk of injury, disease and other harms.

Indigenous peoples disproportionately experience these harms, Katie-Sue Derejko, senior policy analyst, public health for the Assembly of First Nations, told delegates to the CPHA conference. First Nations people are three times more likely to die from overdose, and they are roughly twice as likely to have HIV compared to the rest of Canada.

"There is an unconscionable disparity with this population in Canada," Derejko said. "It's time for all of us to work together to see how this can be reduced."

The public health approach is already gaining traction across Canada at the municipal level. The CPHA report mentions Insite, a supervised injection site in Vancouver as one program that's had "remarkable success in meeting the health needs of those who have injected drugs over the long term and have historically been difficult to reach by conventional services."

Countries such as Switzerland, Norway, Australia and Portugal have made drug policy changes to emphasize prevention, harm reduction and treatment that have also led to reductions in problem drug use and criminal justice overcrowding. "The political climate at the highest level in Canada is not accepting of a lot of these messages right now," Dr. Brian Emerson, a medical consultant in population and public health with the BC Ministry of Health, told delegates. "But when change happens it can happen very quickly, so now is the time to build partnerships and not get discouraged." - Lauren Vogel, CMAJ

CMAJ 2014. DOI:10.1503/cmaj.109-4820 